\title{
EXPERIÊNCIAS ESTÉTICAS NA EDUCAÇÃO INFANTIL - PRÁTICAS PEDAGÓGICAS DESENHADAS PELA ARTE
}

\author{
Andréia Haudt da Silva ${ }^{\mathrm{i}}$ \\ Maristani Polidori Zamperetti ${ }^{\text {ii }}$
}

\begin{abstract}
Resumo: A presente pesquisa contempla a questão: Que espaços e tempos são promovidos pelos professores de Educação Infantil para favorecer a ocorrência de experiências estéticas no cotidiano das crianças? O objetivo é analisar e problematizar a prática docente na Educação Infantil no que se refere às experiências estéticas. A pesquisa ocorreu numa escola do município de Pelotas, RS, e revelou que as professoras reconhecem a importância da arte, buscam utilizá-la no cotidiano, mas sentem um despreparo que acreditam ser fruto da formação acadêmica deficitária que tiveram. Assim, para elas é um desafio pensar propostas que façam uso das linguagens artísticas e esse vem sendo um aprendizado que ocorre na prática.
\end{abstract}

Palavras-chave: Arte; Educação Infantil; Experiências Estéticas; Formação Docente.

\section{AESTHETIC EXPERIENCES IN EARLY CHILDHOOD EDUCATION - PEDAGOGICAL PRACTICES DESIGNED BY ART}

\begin{abstract}
This research addresses the question: What spaces and times are promoted by preschool teachers to favor the occurrence of aesthetic experiences in the daily lives of children? The objective is to analyze and problematize the teaching practice in kindergarten with regard to aesthetic experiences. The research took place in a school in the city of Pelotas, RS, and revealed that the teachers recognize the importance of art, seek to use it in their daily lives, but feel unprepared that they believe to be the result of the deficient academic education they had. Thus, it is a challenge for them to think about proposals that make use of artistic languages and this has been a learning that occurs in practice.
\end{abstract}

Key-words: Art; Child Education; Aesthetic Experiences; Teacher Formation.

\section{Sobre a pesquisa - Experiências estéticas na Educação Infantil}

Este artigo surge da necessidade de compartilhar contribuições da pesquisa de mestrado em educação que teve como tema: Experiências Estéticas na Educação Infantil Práticas Pedagógicas Desenhadas pela Arte. Compreendendo o papel da arte na formação estética das crianças, a pesquisa teve como questão central a indagação: Que espaços e tempos distribuição e reprodução para fins não comercias, com a citação dos autores e da fonte original e sob a mesma licença. 


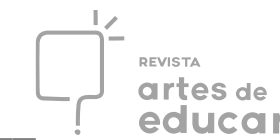

são promovidos pelos professores de Educação Infantil para favorecer a ocorrência de experiências estéticas no cotidiano das crianças?

O objetivo geral consistiu em analisar e problematizar a prática docente dos professores de Educação Infantil do município de Pelotas, RS, no que se refere às experiências estéticas. Deste modo, foi selecionada uma escola de Educação Infantil da rede municipal, tida como referência por apresentar uma proposta e um trabalho que inclui as artes no seu cotidiano e foi desenvolvida uma pesquisa de abordagem qualitativa. No decorrer das observações realizadas na escola, fiz uso de instrumentos para registro fotográfico e de vídeo e utilizei um diário de campo. Estes registros permitiram capturar aspectos da realidade e auxiliaram a reflexão posterior.

Participaram desta pesquisa duas professoras titulares de turmas de Pré 1 e Pré 2. Foi possível perceber que as professoras reconhecem a importância da arte na educação infantil, buscam utilizá-la no cotidiano, mas sentem um despreparo que acreditam ser fruto da formação acadêmica deficitária que tiveram. Segundo as professoras, houve pouco estudo sobre arte durante a formação acadêmica, por isso é um desafio pensar propostas que façam uso das linguagens artísticas, mais ainda, pensar no desenvolvimento de uma educação estética, que tenha por objetivo pensar tempos e espaços que possam favorecer experiências estéticas.

Os tempos e os espaços costumam ser pensados em função da organização da rotina e da necessidade de 'ordenar' a turma para execução das atividades planejadas. [a fim de atenderem necessidades referentes à organização da turma para execução de uma atividade e organização da rotina.] Assim sendo, é necessária a discussão e o estudo do tema a fim de que se possa avançar em direção a práticas pedagógicas que sejam desenhadas pela arte, educando esteticamente nossas crianças, desde cedo.

\section{Por que falar em experiências estéticas?}

A infância é um período marcado por descobertas e por uma relação corporal e sensível com o universo que se apresenta. É por meio das experiências e dos sentidos que a criança passa a conhecer aspectos da realidade.

Temos vivido momentos de pressa, nos quais as experiências se sucedem de forma demasiadamente rápidas e, não raro, é possível testemunhar adultos apressando as 


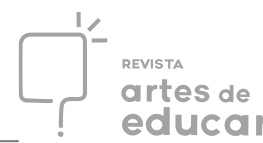

experiências vividas pelas crianças. Larossa diz que a experiência é o que nos passa, o que nos acontece, o que nos toca. A cada dia se passam muitas coisas, porém, ao mesmo tempo quase nada nos acontece (2002, p. 21). O autor chama atenção para a pobreza das experiências que temos vivido. Para ele, a informação, o excesso de opinião, a falta de tempo, o excesso de trabalho nos barram da possibilidade de que algo nos aconteça, isto porque $o$ sujeito da experiência se define não por sua atividade, mas por sua passividade, por sua receptividade, por sua disponibilidade, por sua abertura (p. 24).

A experiência que é estética garante um encontro com o sentir, marcado por uma qualidade de tempo em que os aspectos sensoriais do corpo são privilegiados. O que encanta o olhar, o que é ouvido com maravilhamento, sentido pelo tato de maneira singular, o que aguça o olfato, ganha destaque nas relações que a criança vivencia e isso pede uma prática docente inserida no cotidiano da educação infantil e que busque promover experiências que sejam estéticas.

A experiência estética é singular e subjetiva, não pode ser medida ou avaliada, qualificada como boa ou má, mas pode ser percebida pelos outros através do que impacta/causa em quem vive a experiência, pois altera o estado anterior. Além do mais a experiência estética pode ser narrada pelo sujeito que a vive, a partir de uma proposta que busque instigá-lo a falar sobre o que percebe/sente, como é tocado por aquela experiência, no que aquilo o faz pensar. Por garantir a ligação entre o que se sente e oportunizar a reflexão de sentidos, a experiência estética é uma experiência importante e formadora dentro da educação, pois ao contemplar o que fascina as crianças, cada uma de modo particular e especial, o professor pode favorecer múltiplas conexões e propostas que estimulem um conhecimento ligado às sensações.

As Diretrizes Curriculares Nacionais para o desenvolvimento de propostas pedagógicas na Educação Infantil contemplam a importância de se assegurar vivências que levem em consideração os princípios estéticos da sensibilidade, da criatividade, da ludicidade e da liberdade de expressão nas diferentes manifestações artísticas e culturais.

Para Hermann, a educação que sempre teve atração à unidade pode se beneficiar do reconhecimento da pluralidade de formas de vida estética, pois

[...] a estética atua pelo estranhamento que provoca diante da normalização da moral, contribuindo para desenvolver novas sensibilidades na interpretação de princípios abstratos. A educação é uma ação que se legitima a partir de um determinado ethos, que se orienta por uma ideia de bem. A interpretação estética não é contraditória com a vida ética; antes disso, pode

Revista Interinstitucional Artes de Educar. Rio de Janeiro, V. 5, N.3- pág. 525-550 set-dez de 2019: "Educação: Corpo em movimento." - DOI: 10.12957/riae.2019.45781 
auxiliar nessa justificação, desenvolvendo a sensibilidade para as diferenças de percepção ou de gosto, auxiliando na contextualização de princípios éticos e no reconhecimento do outro e evitando os riscos da uniformização diante do universalismo (HERMANN, 2002, p. 22).

A ética racional em declínio, de acordo com Hermann, necessita da estética, que é capaz de evitar uniformizações e privilegiar o desenvolvimento da sensibilidade. A autora diz que a experiência estética, enquanto um modo de conhecer pela sensibilidade, em que se refugiam a pluralidade e a diferença, passa a se constituir uma via de acesso para a vida ética (HERMANN, 2002, p. 11). Isso elucida a combinação dos princípios éticos e estéticos apontados pelas Diretrizes Curriculares Nacionais para a Educação Infantil, a estética não é normativa, não segue um padrão. A experiência estética está relacionada à reação a algo novo, a sensação que algo dado traz e que muda o estado anterior a sua chegada, a uma percepção que é única para cada indivíduo, mas necessária a todos, pois garante uma gama de descobertas, percepções e relações.

As experiências estéticas consistem em vivências que proporcionam o contato com o que estimula nossos sentidos à contemplação, ao estranhamento, à novidade, à criação, seja um objeto artístico, uma ideia, um elemento da natureza. Essas vivências passam a experiências estéticas por alterarem um estado de estagnação do corpo e do espírito e proporcionarem um conhecimento sensível. Portanto, as experiências podem estar ou não relacionadas às artes.

É necessário destacar a importância de abordarmos a temática da educação estética nos Cursos de Pedagogia, inscrevendo experiências estéticas no cotidiano das futuras professoras.

A produção científica tem defendido a relevância do tema tanto na formação inicial quanto na formação continuada e destaca a importância de uma prática docente que propicie experiências que contemplem as linguagens artísticas numa perspectiva de formação estética.

\section{Espaços e tempos como possibilidades de experiências estéticas}

A criança tem aquele poder do agora, desfrutam tanto do tempo que lhes é agradável que se puderem pedir mais uma vez pela história de que tanto gostaram, pedirão "de novo, de novo!". 


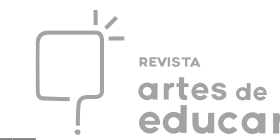

Os tempos são marcados pela qualidade das vivências e pelo espaço em que ocorrem, por isso, costumeiramente ao falar sobre tempos na educação infantil se fala também em espaço. A organização de espaços e tempos nesta etapa é estabelecida em conformidade a documentos do MEC e é objeto de estudo de alguns pesquisadores.

A forma como o professor organiza os espaços e tempos na educação infantil pode refletir como ele compreende o modo de se relacionar das crianças. $\mathrm{O}$ modo como ele espera que as crianças interajam entre si, com os adultos, com os brinquedos, com os objetos e mobiliário, são elementos que refletem tendências e marcam sua prática docente.

Barbieri diz que o espaço tem intenção e orienta a ação, ela destaca que o espaço convida, suscita ritmos, transparece segurança, conforto. Há por isso espaços que permitem que nos sintamos valorizados e à vontade, que nos impulsionam à criação. A autora traz algumas questões que suscitam a reflexão das práticas docentes quanto à organização dos materiais e dos espaços na sala de aula: Como você os organiza em sua sala? Sempre da mesma maneira, ou de formas variadas? Sempre os mesmos ou inventa novas possibilidades? (BARBIERI, 2012, p. 52).

É gratificante perceber as experiências que somos capazes de proporcionar às crianças através de uma prática que leva em conta a organização dos espaços de forma a suscitar o olhar curioso, o toque, a escuta, a descoberta. Um pano que delimita um espaço na sala, uma caixa, um painel para pintura, um móvel, um lugar para exposição de criações, um lugar para criações e tantos outros, pois no espaço da sala cabem tantos outros espaços.

Para isto, é necessário pensar propostas que favoreçam experiências estéticas, tendo o professor como promotor, mediador e potencializador de experiências que provocam os sentidos. Ele observa, entra em cena, constrói histórias, canta, desenha, dança, se faz ser brincante e artista.

A organização do tempo é fundamental, mas organizá-lo não significa aprisioná-lo. Os tempos não devem transcorrer sem uma preocupação estética. E no que consiste essa tal preocupação estética?

Consiste em um tempo em que são observadas as interações entre as crianças, o que lhes agrada, descontenta, o que causa euforia, indignação, nisto o professor não é um mero observador, ele observa com o propósito da ação, com o objetivo de propor alternativas de uso do tempo, de criação de espaços, de mundos de faz-de-conta, de experiências do mundo real. A marca de um tempo permeado por uma preocupação estética se faz pela atenção às 
emoções ocorridas nos espaços, pela ação que propõe um conhecimento sensível das relações e dos conhecimentos acumulados pela humanidade.

A atenção pelo tempo não se dá através dos olhos nos ponteiros do relógio, se dá ao cuidado com a criança que ainda desenha quando chegou o momento de ir ao refeitório, não é porque aquele momento de criação precisa ser pausado que o desenho é recolhido e guardado, ou exposto. Estabelece-se com a criança uma forma de dar continuidade àquele processo criativo, perguntando se ela quer concluir mais tarde, se prefere continuar na escola ou em sua casa, pois esta atenção preocupa-se com o processo vivenciado pela criança e a valoriza.

O tempo não deve ser desprovido de movimento. A rotina é uma forma de organizá-lo, mas não de engessá-lo. Como exemplo: o momento livre não precisa ocorrer sempre da mesma forma, visto que ele é pensado e planejado pelo professor, ele pode conter elementos surpresas, que agucem novas brincadeiras e relações, as atividades dirigidas quanto mais diversificadas mais enriquecerão o olhar das crianças às produções artísticas, culturais e científicas produzidas.

A pedagogia de Reggio Emilia considera o espaço como um ambiente que educa as crianças. Gandini (2016, p. 148) salienta que:

A fim de agir como um educador para a criança, o ambiente precisa ser flexível; deve passar por uma modificação frequente pelas crianças e pelos professores a fim de permanecer atualizado e sensível às suas necessidades de serem protagonistas na construção de seu conhecimento.

O cuidado com a aparência do ambiente nas escolas italianas reflete uma intenção que se destaca: a valorização da interação e da comunicação entre as crianças e de todos os que vivem o cotidiano da escola.

Concordo com Gandini (2016), ainda quando cita Greenman (1988):

Um ambiente é um sistema vivo, em transformação. Mais do que um espaço físico, inclui o modo como o tempo é estruturado e os papéis que devemos exercer, condicionando o modo como nos sentimos, pensamos e nos comportamos, e afetando dramaticamente a qualidade de nossas vidas. O ambiente funciona contra ou a nosso favor, enquanto conduzimos nossas vidas (GREENMAN, 1988, p. 5 apud GANDINI, 2016, p. 146 - 147).

E o ambiente, aqui compreendido também como espaço, imprime marcas dos tempos que priorizamos. Espaço que prevê o bem-estar social e também individual das crianças manifesta que os aspectos coletivos e individuais são respeitados, espaço que prevê um 


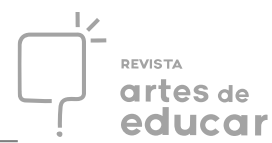

ambiente de acolhida aos pais demonstra que a presença deles é bem vinda. Segundo Gandini (2016, p. 147) há uma conexão entre o tempo e o espaço.

A consideração pelas necessidades e pelos ritmos das próprias crianças molda o arranjo do espaço e do ambiente físico enquanto, por sua vez, o tempo de que dispomos permite o uso e o desfrute, no ritmo da criança desse espaço cuidadosamente elaborado.

Vale destacar que o espaço é pensado para atender às recomendações de uma pedagogia que busca o respeito às necessidades e ritmos das crianças. Trata-se de uma pedagogia sensível às ações: o exercício dessa sensibilidade ao pensar e estruturar espaços é papel do professor e pode permitir, ou não, o favorecimento de experiências estéticas.

Meira e Pilloto (2010) contribuem para a reflexão a respeito dos ritmos quando formulam a indagação: Como modular olhares apressados, controlar o ritmo das ações para que delas possam emergir potencialidades poéticas e estéticas?

O encaminhamento de uma resposta passa por investir em uma educação que privilegia o aperfeiçoamento do olhar, que busca um tempo para a promoção de capacidades criativas.

Ao tratar de minúcias da vida cotidiana e abordar a repetição das rotinas, Martins Filho (2013) fala da importância de se prestar atenção aos motivos pelos quais fazemos as coisas de um determinado jeito a fim de que as práticas na educação infantil não estejam presas a modelos que conformam a vida cotidiana e depreciam as rotinas. $\mathrm{O}$ pesquisador destaca que

\begin{abstract}
As ações nas rotinas que se repetiam, contribuíam para as professoras perderem gradativamente o entusiasmo e o encanto pela docência. Percebi que as ações praticadas no dia a dia eram destituídas de sentido e significado, isso tanto em relação aos interesses e às expectativas das crianças, como às próprias expetativas do coletivo de professoras quanto ao que se faz e refaz cotidianamente no CEI. Posso dizer que a complexidade da vida era reduzida a um fazer-fazendo sem uma reflexão do que sejam as especificidades da prática da docência na educação infantil (MARTINS FILHO, 2013, p. 107).
\end{abstract}

O autor chama a atenção para uma ação reflexiva sobre as minúcias da vida cotidiana na Educação Infantil, especialmente no que se refere ao dia a dia da docência e destaca que atender a multidimensionalidade da vida cotidiana considerando tempos-espaços e atividades poderá contribuir para nos desafiar a olhar com olhos livres e bem abertos para o que se está 


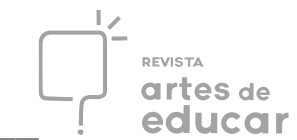

fazendo (MARTINS FILHO, 2013, p. 108). Pois, segundo ele, a rotina rígida e repetitiva, beira a mesmice, reduz possibilidades de autoria e autonomia. Acrescento que priva de criatividade e de novas provocações, provocações que visem ao exercício da criação, de novas descobertas, de interação no grupo social e de ação autônoma.

Vale lembrar que a estética como campo de estudo sobre o sensível apresenta também uma aproximação com a ética, como se lê:

A estética, além de tornar-se um campo de estudos sobre a experiência sensível, converteu-se num modo de pensamento que responde às preocupações éticas da vida contemporânea. Ela ocupa-se de pensar diferentes formas de exercer a criatividade, os problemas da sensibilidade que se revelam em obras, eventos, programas de conexão entre o corpo e o espaço. Neste pensar, nunca como antes, a conexão com o tempo foi percebida de modo tão intenso. O tempo é o tema mais desafiador da reflexão estética relacional atualmente (MEIRA; PILLOTO, 2010, p. 85).

É sobre a qualidade de tempo ou a falta dele que se debruçam o olhar ético, estético e político. Por mais que a estética apresente aspectos relevantes suficientes para a abordagem educacional, ela não se encerra nela mesmo, ela dialoga com princípios de uma política e de uma ética voltada para os aspectos sensíveis que valorizam o bem comum, a promoção da autonomia, os direitos de cidadania, o respeito às diferentes culturas etc.

É necessário que o tempo seja pensado como um facilitador de experiências estéticas, do contrário, estaremos nos empenhando em reproduzir as ações de um mundo que sufoca o olhar da criança, reproduziremos espaços que se configuram como um arsenal de forças produtivas e mecanizadas, que produzem sempre do mesmo. O tempo na infância não é o tempo do adulto moldado a fazer rapidamente várias coisas ao mesmo tempo, os espaços não se restringem basicamente ao do lar e do trabalho. É importante lembrar que as crianças possuem um ritmo muito próprio, e que cada uma delas possui o seu.

Cada criança e grupo de crianças tem seu próprio ritmo, ao qual devemos estar atentos. É comum que as crianças que chegam à escola pela primeira vez se concentrem por pouco tempo em suas produções. Sua concentração vai se ampliando gradativamente, conforme o interesse, envolvimento e interação com o professor, que pode sugerir outros materiais $\mathrm{e}$ procedimentos (BARBIERI, 2012, p. 55).

A criança tem um tempo que se configura pelas experiências que vive, que elas sejam estéticas! Para isso é necessário ter clara a importância do professor em organizar tempos, espaços, materiais e interações. Barbieri fala de um espaço-oficina que deve ser acolhedor, Revista Interinstitucional Artes de Educar. Rio de Janeiro, V. 5, N.3- pág. 525-550 set-dez de 2019: "Educação: Corpo em movimento." - DOI: 10.12957/riae.2019.45781 
apropriado a montagens diversas: crianças ao redor de mesas, no chão utilizando diferentes materiais, permitindo uma relação espontânea e criativa.

Na Educação Infantil, existe a possibilidade de oferecer um tempo ampliado para cada proposição, de modo que a criança possa usufruir um período generoso para realizar seus trabalhos - mergulhar e desenhar em muitos papéis e, se esse movimento continuar intenso, poder continuar no dia seguinte. Sempre que possível, o espaço usado deve ser o ambiente de oficina, seja em um espaço permanente ou criado na própria sala de aula (BARBIERI, 2012, p. 54).

Desta forma, é preciso favorecer o acesso aos materiais para que as ideias ganhem movimento e sejam concretizadas. Vale lembrar que mais importante que o produto final é o processo. O que possibilitamos no decorrer das experiências que propomos? A cópia? A padronização? Possibilidades de expressão? A construção de narrativas? Como é rico ouvir a história de um desenho! O enredo de uma brincadeira! Uma música criada pelas crianças!

Os espaços podem servir para o que elas quiserem, casinha, salão de beleza, posto de gasolina, hospital, e por isso precisamos dispor arranjos dos mais variados para contemplar as infinitas possibilidades que podemos proporcionar, dentro da sala e em outros ambientes da instituição.

$\mathrm{O}$ espaço enquanto marca do nosso convite às práticas infantis, convida a quê? O que informa?

Imaginemos uma sala decorada nas cores rosa e azul, sendo que na parte rosa estão os nomes das meninas e na parte azul os nomes dos meninos. Simples decoração? Não. Há um discurso sendo informado por essa "ornamentação" da sala, que revela questões de gênero, dentro das quais as cores têm sexo. Quem disse que azul é de menino e rosa é de menina? (OSTETTO, 2017, p. 59).

Se nossa intenção for moldar o tempo da criança e o conformismo dela com os espaços, porque é isto que a vida lhe reserva, reduziremos ainda mais o saber sensível de nossa sociedade em função de um saber intelectivo desprovido de qualquer sensibilidade, reforçaremos discursos de desigualdade e nos afastaremos dos princípios éticos e estéticos que permitem o diálogo pautado na sensibilidade ética.

As artes possibilitam esta conexão com o saber sensível e desenvolvem uma educação estética e ética, que relaciona a vida, o conhecimento e a sensibilidade. Ela está nas brincadeiras de faz-de-conta, na criação de personagens, de narrações, nas músicas, na 


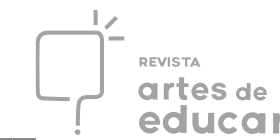

produção de desenhos, de esculturas de massinhas de modelar, de argila, nos filmes que assistimos, na dança, nas histórias que escutamos, na apreciação de obras as mais diversas.

Sendo assim, que experiências estéticas o professor promove a partir dos espaços e dos tempos? Em que momentos ocorre? Durante quanto tempo? Em que espaços? Os espaços são pensados com este objetivo?

\section{Ambiente privilegiado para a pesquisa - a escola em foco}

Ao buscar escolas para a realização da pesquisa, percebi que procurava por um ambiente no qual a arte tivesse papel essencial no processo educacional das crianças, logo seria interessante buscar uma escola de educação infantil que fosse conhecida no município de Pelotas por apresentar uma proposta de educação conectada às artes.

Já tinha ouvido falar numa escola com essa característica e acolhi a sugestão de tomála como campo para a pesquisa. Ali eu poderia ter contato com professores que contam com apoio da instituição para propostas que contemplam o universo artístico e porque não dizer, dos sentidos.

A escola fica situada numa das praças da cidade, o que me encantou. Árvores ao redor, pessoas passeando de bicicleta, algumas trabalhando, outras se conversando. O espaço físico da escola é amplo, iluminado, possui boa ventilação; a escola se apresentava bem cuidada; possui três salas de aula com turmas de Pré 1 e Pré 2, uma sala de artes, cozinha, secretaria, direção, sala de professores, pátio coberto e ao ar livre.

Duas professoras foram sujeitos da pesquisa, pois uma das turmas estava sem professora quando cheguei à escola, também o tempo disponível para observação permitiria um contato mais próximo com duas turmas e não três. A professora Esmeralda, 45 anos, formação em Magistério e Pedagogia, conta vinte e sete anos de docência e a professora Rubi, 32 anos, formação em Pedagogia, seis anos na docência.

Os nomes das professoras são fictícios. Decisão que partiu das próprias entrevistadas perante o questionamento da utilização ou não de seus nomes reais. Já a escolha por estes nomes decorre de uma experiência que vivi com as crianças num dia de observação; elas compartilharam comigo a busca e a pesquisa por pedras preciosas, conversamos por um tempo sobre a qualidade das pedrinhas que eram encontradas no pátio da escola, o entendimento sobre a preciosidade ou não das pedrinhas era diverso, referia-se a tamanho, 


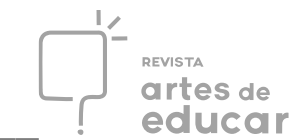

brilho... Por isso criei uma analogia: as professoras são como pedras preciosas, pois possuem um potencial riquíssimo para encantar e um alto valor que embora não seja quantificado pelo mercado, gera uma riqueza de experiências que pode tornar sensível e bela a vida das crianças.

O ambiente da escola é muito acolhedor e a instituição tem uma preocupação muito forte com a ampliação de repertórios culturais das crianças e a disponibilização de espaços de fruição e criação de artes.

Inicialmente as observações foram realizadas na turma da professora Rubi, um Pré 2. Esta turma, composta por vinte crianças, mostrou-se muito afetuosa, atenta à professora e me recebeu com muita curiosidade: queriam saber o que eu fazia ali, o que eu escrevia, certas vezes me viam como outra professora na sala, que poderia auxiliá-las ou dar-lhes alguma permissão. Quando partilhavam algo comigo eu estava atenta e aproveitava para conhecê-las um pouco mais.

Estar atenta a propostas que possam favorecer experiências estéticas implica conhecer um pouco as crianças, identificando quando há euforia, encantamento, quando o olho vibra, quando a voz quer comunicar algo. Foi isso que procurei fazer, observar não somente as propostas lançadas, como também a resposta das crianças frente ao que era proposto, para perceber o que as tocava de forma especial, o que trazia uma qualidade de tempo e entrega permeada por uma experiência estética.

Transcorrido o tempo de observação no Pré 2, iniciei as observações no Pré 1 , com a professora Esmeralda. Esta turma já havia me visto pela escola, então creio que para muitos era como se eu pertencesse àquele ambiente. Assim como no Pré 2, partilhavam experiências comigo, especialmente nos momentos em que estavam brincando, me percebiam muito atenta às suas experiências e as dividiam comigo.

\section{Reflexões a partir dos encontros de observação e das entrevistas}

No primeiro dia, em ambas as turmas, observava de forma especial o espaço físico, o que havia nas paredes, a disposição dos brinquedos, das mesas. Era uma forma de me conectar com o que vinha acontecendo antes da minha chegada, nas semanas seguintes ainda adotava esta prática, observava o ambiente e procurava saber o que haviam vivenciado nos $\mathrm{s}$ dias anteriores. 
O espaço físico da sala do Pré 2 é bem diversificado e colorido, possuindo local para os brinquedos, um painel colorido com trabalhos das crianças, um espelho para que estas possam se ver e as mesas nas quais são realizadas as atividades ficam agrupadas de forma que possam abrigar até seis crianças juntas.

Nas paredes é possível perceber atividades que foram realizadas pelas crianças. Já que se assemelhavam em cores e formatos, percebi que a utilização da folha se deu da mesma forma, em posição paisagem, nas atividades referentes ao Boto Cor de Rosa e em posição retrato nas atividades referentes ao Saci. Cabem alguns questionamentos: as crianças casualmente colaram os personagens na mesma posição? Que possibilidades de criação a partir dos personagens de dobradura foram potencializadas? A criação de desenho com materiais diversos? A criação de narrativas orais?

O espelho da sala, embora pequeno, está colocado em uma posição central e permite uma visibilidade ampla da sala. Embora um de seus objetivos nas salas de educação infantil seja permitir o desenvolvimento do esquema corporal das crianças, pouco foi possível vê-las observando-se no espelho. Convém refletir sobre as experiências que podem ser favorecidas a partir do uso do espelho na sala, experiências estas, para além do desenvolvimento do esquema corporal, que favoreçam também a observação do grupo, das características pessoais de cada um, a experiência da vivência de papéis através de fantasias, maquiagens, e o que mais elas inventarem. É válida a reflexão de como este recurso pode permitir experiências estéticas e tantas outras.

A configuração da sala, da organização do espaço, se altera na medida da exposição de trabalhos das crianças nas paredes e de painéis montados pelas professoras. As mesas costumam estar agrupadas da mesma forma, tal como os brinquedos que costumam estar dentro das caixas.

Na turma de Pré 1 a disposição da sala difere um pouco, pois não há murais com números e letras e sim murais decorativos. Estes foram confeccionados pelas professoras, possivelmente com a intenção de tornar a sala mais bonita e agradável. Enquanto espaço das crianças e para as crianças, a sala é um ambiente essencial para valorizar o protagonismo infantil, através de murais feitos pelas crianças e com a participação delas, através da disponibilização de espaços, nos quais elas possam imprimir suas marcas, desenhando nas paredes, expondo seus trabalhos. 
Que protagonismo as imagens nas paredes defendem? Esta é uma pergunta que nos ajuda a pensar no cotidiano e está intimamente ligada ao modelo de infância que temos em mente.

Barbieri (2012), ao defender a importância de contrapormo-nos à padronização das atividades, dos espaços e intervenções didáticas que cerceiam o processo de criação diz que:

Trabalhar de uma maneira comprometida com o protagonismo da criança, para que ela seja o fio condutor, exige um deslocamento nosso, sair do nosso umbigo de professor, olhar para o outro de fato e perceber nossas lacunas. O que está faltando em mim como professor, do que preciso? O que preciso arrumar nesse espaço, como ele pode melhorar? (BARBIERI, 2012, p. 150).

Para isso é necessário um exercício de autocrítica: a autora fala da importância de verificarmos se estamos trazendo assuntos da televisão de baixíssima qualidade ou heranças culturais significativas do nosso povo.

A brincadeira é a atividade principal da criança; é através dela que a criança se relaciona com os objetos, que assume papéis que percebe no seu cotidiano, que vivencia potencialidades. Ao observar a sala do Pré 1, noto que os brinquedos ficam expostos, não há brinquedo inalcançável. No mais o ambiente é bem parecido ao da sala do Pré 2, os materiais para atividades manuais estão nos armários, há um tapete no qual ocorre a contação de histórias e a roda de conversa.

O espaço da sala é acolhedor, bem ventilado, iluminado, limpo. Quanto à disponibilidade de materiais na sala, é possível perceber que os brinquedos e livros são de fácil acesso, no entanto, os materiais para atividades manuais não são, assim como na sala do Pré 2, estes materiais ficam guardados no armário. O que me lembra Zamperetti (2007), quando fala em sua dissertação que os materiais para pintura ficavam nos armários altos e fechados, e assim sendo, eram inalcançáveis para ela e as demais crianças; (isso no ano em que cursou a pré-escola,) mas que:

As imagens em mim configuravam-se, transformando-se em sonhos, pesadelos, possibilidades, aventuras, estórias. Precisava colocá-las no papel, dar vazão à minha criatividade infantil. A cabeça estava sempre funcionando, criando algo. Eu era curiosa. Esta curiosidade me fazia ir além, auxiliando-me a transpor as barreiras dos armários fechados e as determinações dos professores: não pode pegar, não pode sentir. A curiosidade natural da idade me fazia ter mais vontade de saber e aprender sobre o mundo. (ZAMPERETTI, 2007, p. 15-16) 


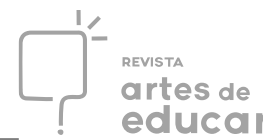

Este relato me levou a refletir sobre as possibilidades criativas que precisam ser disponibilizadas às crianças. Através do acesso aos materiais de atividades manuais como massinha, lápis de cor, giz de cera, pincéis, tintas, entre outros.

Há momentos em que as crianças brincam livremente e outros em que realizam atividades propostas pelas professoras. Nas atividades livres percebe-se que há construções de narrativas criativas, que vivenciam papéis, são momentos em que as professoras podem brincar junto, criar histórias, assistir a espetáculos,...

Quanto ao espaço, Oliveira (2012) aponta que estes devem estar adequados ao tipo de atividade destinada à criação que será desenvolvida. Para ouvir música é necessário um espaço silencioso, em que haja a opção das crianças se sentarem para uma escuta mais atenta, pode haver almofadas ou outros materiais que ajudem a amortecer ruídos externos; já para a dança, são necessários espaços livres de mobiliário, que permitam a livre movimentação e exploração do corpo; para atividades manuais as crianças precisam de espaço para se movimentar em torno das mesas, cavaletes, painéis, etc, a fim de que possam observar e apreciar as imagens. Oliveira (2012, p. 275) destaca que

[...] o professor também pode usar o próprio espaço como objeto de criação, discutindo com as crianças a estética de cada local. O que colocar nas paredes? Qual o melhor lugar para expor os painéis com desenhos e pinturas? Que pôsteres ou quadros são mais interessantes como referência estética para as crianças?

Além do mais, o parque também pode ser transformado em um enorme ateliê, como sugere a autora, com espaço para riscar o chão, com paredes preparadas para acolher e tornar possíveis as produções infantis. Um canto com sombra próximo a uma árvore pode ser uma alternativa para uma roda de conversa, de leitura, pois todos estes aspectos em conjunto tornam o espaço não apenas uma variável determinante no planejamento do professor, mas, principalmente, objeto para as apropriações criativas das crianças (OLIVEIRA, 2012, p. 275).

Nas turmas observadas a rotina é costumeiramente conduzida pela professora titular: as crianças costumam chegar, sentar nas mesinhas, comem eventualmente uma fruta, fazem as atividades propostas, ouvem uma história e fazem atividade referente à mesma, outras atividades de memória, percepção, equilíbrio, coordenação, também costumam ser planejadas.

As crianças se mostraram muito curiosas desde as primeiras observações, vinham me perguntar o que eu estava fazendo, me mostravam suas atividades, contavam Revista Interinstitucional Artes de Educar. Rio de Janeiro, V. 5, N.3- pág. 525-550 set-dez de 2019: "Educação: Corpo em movimento." - DOI: 10.12957/riae.2019.45781 


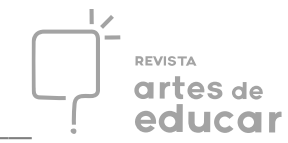

acontecimentos.... Percebiam que eu estava ali para conhecer um pouquinho da rotina deles e compartilhavam experiências que viviam e coisas que lhes chamavam a atenção.

A pesquisa aprofundou as discussões sobre o tema a partir das categorias: Arte - mais que um recurso interessante; Formação para lançar olhares e escutas sensíveis; Planejamento flexível que permita o encantamento com o que acontece no meio tempo e Tempos e Espaços para deslumbramentos.

A seguir abordarei a categoria que se refere à formação, por compreender que a formação acadêmica deficitária tem inibido a percepção da arte para além de um recurso interessante; o Planejamento flexível como possibilidade para encantamentos que aconteçam no meio tempo e os Tempos e Espaços como ambientes que educam e que podem causar deslumbramentos.

\section{Formação para lançar olhares e escutas sensíveis}

Durante as entrevistas as professoras comentaram alguns aspectos referentes à formação:

Eu vou te dizer que a arte eu chamo de terceiro olho. Porque tu vai (sic) trabalhar com as crianças um jogo e aquele jogo mostra tantas coisas da vida deles que tu começa (sic) a compreender porque cada um é assim. Acho que pra ti (sic) trabalhar uma temática, alguma coisa mais específica que lida com sentimentos, tem (sic) que ser um profissional que vai saber conduzir, como vai trabalhar com isso? Por exemplo, eu adoro harmonização, tentei esse ano de tarde, eu dei três harmonizações; fui ali coloquei uma musiquinha calma, trabalhei o toque, tocar no colega...fiz isso porque a colega estava comigo, não me sinto habilitada a fazer hoje, porque hoje não é o dia certo, hoje estão a mil, não fecha. Lidar com coisas específicas da arte envolve sentimento? Envolve. Envolve emoção? Envolve. Envolve criatividade? Envolve. Mas tem que ser um especialista, porque se pega uma pessoa leiga, sem conhecimento, ela pode deixar uma criança ridicularizada para o resto da vida, ou ela pode imaginar mil coisas e até expor a criança ao ridículo (PROFESSORA ESMERALDA, 29/11/2018).

Aqui a professora me falava sobre a relação das crianças com propostas que envolvem a criação, os sentidos. Ela citou uma experiência envolvendo a música, que costumava desenvolver com as crianças. Falou que é necessário estar atento ao contexto para perceber se a atividade servirá ao propósito, da importância de sentir o "timing" do grupo, mas enfatiza 


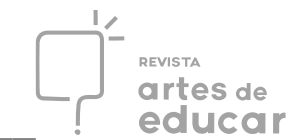

que para lidar com os sentimentos, com a emoção, a criatividade, precisa-se passar por uma formação para este fim, do ponto de vista da professora "tem que ser um especialista".

O especialista ao qual a professora se refere pode ser o profissional de artes, de música, do teatro, da dança. Para a professora as habilidades pertinentes às artes são desenvolvidas por profissionais especializados para este fim, que passaram por uma formação acadêmica.

Segundo Perissé (2014, p. 41-42), a formação estética contribui para a vida intelectual e profissional do professor. Formar-se é entrar em contato com valores de toda ordem. Especificamente, o contato com valores estéticos (e também com informações, dados, terminologias estéticas... deve ser ocasião para vislumbrarmos projetos de vida humanizadores. $\mathrm{O}$ autor destaca que é no contato de cada um com a arte, com uma obra, que se estabelece um encontro humano e humanizador, que se percebe aquilo que um artista sentiu, que habita com ele na obra de arte. Com isso considero importante destacar que é necessário ao professor estabelecer esse mesmo tipo de encontro com as crianças, suas produções e expressões, por isso a formação estética no decorrer da formação acadêmica e na formação continuada dos professores é tão importante.

Quanto à formação dentro do curso de Pedagogia ou curso por iniciativa própria, a professora Rubi disse:

Não, nunca tive. Foi uma cobrança do meu eu. Pensava: será que eu vou conseguir? Quando cheguei aqui não foi fácil, tem que fazer eles (sic) produzirem, produzirem, produzirem, mas no fim eu fui vendo que não é o tanto quanto me falaram. Eu me encontrei até, gostei, gosto desse método, dessa metodologia de ensino daqui (PROFESSORA RUBI, 29/11/2018).

Neste momento da entrevista ela falou dos desafios ao ingressar numa escola com uma proposta de ensino voltada às artes. Inicialmente trabalhar numa escola assim lhe trouxe certa preocupação, representou um desafio, visto que nunca havia tido aproximação tão frequente com as artes.

Ambas as professoras destacaram que no curso de pedagogia viram muito pouco sobre as artes.

Não, não. Eu sempre procurei fora, porque eu fazia oficinas de arte, há muitos anos atrás existiam oficinas de aquarela, oficina de tradição do Rio Grande do Sul, mas isso na década de 80 (PROFESSORA ESMERALDA, 29/11/2018). 
Ostetto e Silva (2018, p. 194) apontam que

Segundo pesquisa realizada pelo GPAP - Grupo de Pesquisa Arte na Pedagogia, da Universidade Mackenzie, que teve por objetivo mapear a presença da Arte nos cursos de Pedagogia no Brasil (MARTINS; LOMBARDI, 2015), a inserção da arte nos currículos é ainda ínfima, quando não inexistente.

O que vai ao encontro do que foi dito pelas professoras durante a pesquisa. A professora Esmeralda comentou que momentos mais próximos de contato com as artes ocorreram antes da sua formação acadêmica, ela que é artesã e que busca em sua vida pessoal uma aproximação com as artes, mas que considera importante ter um conhecimento para lidar com o universo das artes com as crianças, buscou em sua vida uma aproximação com o artesanato e as artes visuais por interesse particular, mas acredita que a arte na educação deve ser abordada por profissionais que sejam especialistas, profissionais habilitados e formados para esse fim, considera de suma importância a formação profissional.

A professora Rubi ao citar alguma referência que tenha tido com relação às artes durante o curso de Pedagogia disse:

Tive uma professora que, eu acho que de uma forma sutil, não tão ampla assim, como talvez devesse ter contribuído, me deu assim um certo leque sabe? Sim, a gente pode e é importante a arte! Não só pra quem é criança, mas como pra qualquer um (PROFESSORA RUBI, 29/11/2018).

A arte costuma nos dizer que é possível criarmos. Algo muito importante a docente do curso de pedagogia da professora ensinou: a gente pode! A arte não ensina receitas ou formas de reprodução, por mais que ela exija técnica e repetição para o alcance de algumas habilidades, técnica desprovida de sentimento parece mero exercício.

$\mathrm{Na}$ infância não estamos a moldar artistas. Priorizar uma educação associada às artes, é buscar uma educação que se conecta com um universo de sensibilidade, imaginação, criação, fruição. Portanto não buscamos uma infância de reprodutores e sim de autores, sujeitos de suas ações, convictos de suas potencialidades.

Trago um dos registros para abordar a importância do olhar atento e da escuta às relações que as crianças estabelecem entre si:

"Hoje no parque, Luzia me trouxe uma pedrinha: - Olha, tia, uma pedra preciosa!

Um menino, antes que eu comentasse qualquer coisa disse: - Nem é preciosa! 
Perguntei: - É?! E o que precisa para ser preciosa?

O menino pensava enquanto a menina dizia: - É preciosa sim! Não é? (disse ela buscando uma afirmação minha)

- É! E um amor! (lhe disse olhando para a pedrinha, que por ser tão pequena, ela segurava com muita delicadeza)

Outras crianças chegam, eu mexo no celular como se estivesse vendo a hora, e inicio a gravar:

- É uma pedra preciosa! Ela é meio de vidro! (diz o Arthur se aproximando)

- Humm

- Tipo essa daqui oh! (vem outra menina mostrando sua pedrinha)

- Essa é preciosa?

- Sim, é preciosa essa! (diz o Arthur)

- Essa é?

- E essa aqui também! (diz uma menina)

- É muito pequena pra ser preciosa (diz o Arthur)

- É ? E Amanda aquela ali é preciosa ou não é?

A menina olha com atenção e observa, sem responder

- O quê que a gente faz pra saber se uma pedra é preciosa ou não é? (pergunto)

- Elas nem sabem alguma coisa, elas nem sabem (diz um outro menino se aproximando)

- E você sabe como é que faz pra saber se é preciosa?

- O Arthur e eu, a gente tava lá atrás da árvore, aí tinha umas pedras preciosas, mais grande, e que tem umas, que elas nem sabem, eu tô bem pertinho (diz o menino olhando esperto para trás da árvore)

- Humm, então tem que ser grande?

- É!!

- E o que tu acha Luzia?

- Hm... eu acho que a pedra é preciosa (encerra a Luzia continuando a segurar a pedra preciosa)

Eu paro de gravar e em seguida ela me pede: tia, guarda? Eu guardo com cuidado no meu bolso e pergunto, até quando a gente voltar pra sala? Ela diz: É!

Na sala quero lhe entregar e ela diz: depois. Quando ela pega a mochila na hora de ir embora eu digo: "Luzia, tô com algo teu aqui". Ela vai em minha direção e me estende a Revista Interinstitucional Artes de Educar. Rio de Janeiro, V. 5, N.3-pág. 525-550 set-dez de 2019: “Educação: Corpo em movimento." - DOI: 10.12957/riae.2019.45781 
palma da mão para eu colocar sua pedrinha, dizendo: "obrigada tia!, sai com um sorriso de orelha a orelha, olhando a pedrinha" (Diário de campo e transcrição de áudio de vídeo - Pré 2 $-28 / 08 / 2018)$.

Essa nossa conversa sobre pedras preciosas, e outras que tínhamos me fez perceber que ocorrem experiências riquíssimas das crianças com o meio que as cerca, que não estão planejadas, mas que necessitam de olhares e escutas sensíveis e atentas.

Vecchi (2017, p. 88) destaca que:

Como qualquer outra atividade humana, a Pedagogia, de maneira particular, precisa de ouvidos atentos para o entorno, porque se ocupa de educação e de uma parte preciosa da humanidade, as crianças, caso contrário, arrisca perder os contatos com os protagonistas das próprias reflexões e do próprio agir, as crianças e os jovens, e transformar-se em uma disciplina baseada, simplesmente, em uma série de regras a aplicar, com frequência, autorreferenciais demais, seguras de si e cristalizadas no tempo.

Desta posição da autora, quero enfatizar que precisamos de "ouvidos atentos para o entorno". Vea Vecchi costuma destacar essa necessidade de 'enlaçar escutas sensíveis. Isso é possível quando a atenção ao processo se faz presente. É possível perceber que as crianças estão encantadas mais com a exploração e o processo daquilo que vivem do que com o produto. Um bonequinho que acabaram de modelar, em seguida vira um cachorrinho, uma pizza.

Outro registro do meu diário diz: as crianças recebem massinha de modelar. Observo elas utilizarem as forminhas, depois de um tempo me aproximo e pergunto o que estão criando? O primeiro menino me diz: - É um carrapatinho, desses que fica no cachorro (e o carrapatinho tem um corpo imenso, conforme a figura 1, mesmo sendo denominado no diminutivo). 


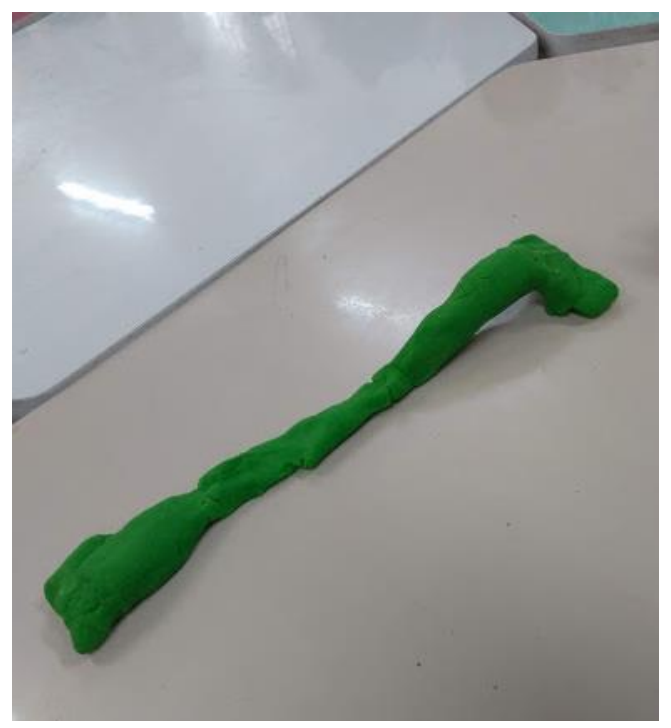

Figura 1 - Carrapatinho - Pré1.

Fonte: Registro fotográfico da pesquisadora, 2018.

Em outro registro do diário de campo, Isadora faz um urso com a forminha e me mostra. Digo: - Que legal e que tal criar um da sua imaginação? O que tu achas? Ela parece surpresa e balança a cabeça de modo afirmativo. Me diz: me ajuda? Respondo que sim e pergunto se posso fazer a cabeça do ursinho na forma de uma bolinha. Ela vai me acompanhando e moldando a massinha, verificando o tamanho das partes. Construímos o ursinho, conforme a figura 2 , enquanto outras crianças também mostram o que estavam fazendo.

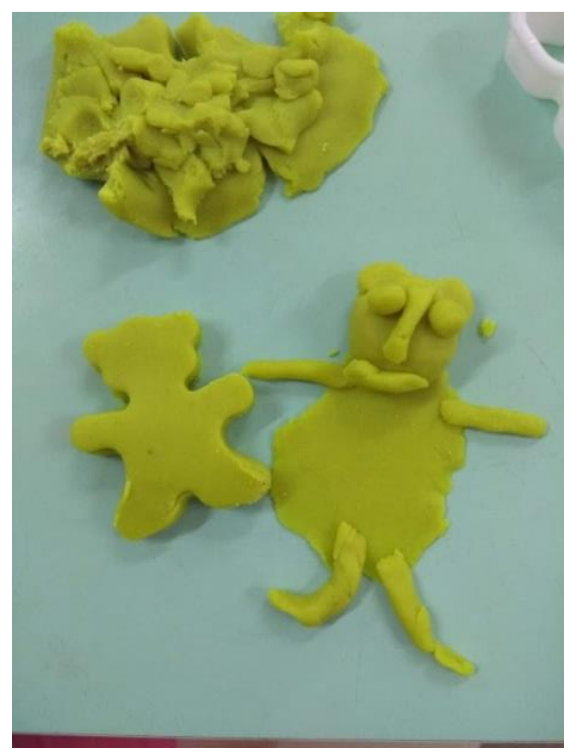

Figura 2 - Ursinho - Pré1.

Fonte: Registro fotográfico da pesquisadora, 2018.

Revista Interinstitucional Artes de Educar. Rio de Janeiro, V. 5, N.3-pág. 525-550 set-dez de 2019: "Educação: Corpo em movimento." - DOI: 10.12957/riae.2019.45781 
Conforme a figura 3, o Eduardo faz um cachorro com mochilinha que vai para a escola.

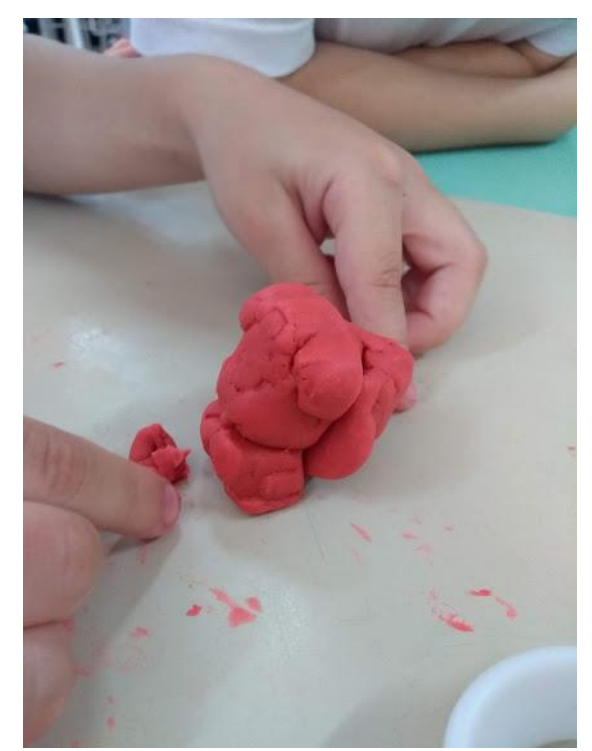

Figura 3 - Cachorro com mochilinha.

Fonte: Registro fotográfico da pesquisadora, 2018.

O Rodrigo vendo que vou sentar do lado de um coleguinha diz: senta aqui do meu lado. O lanche chega e as crianças lamentam, estão contando histórias entre o dragão e o cachorrinho de mochila, achando uma graça a elefanta de laço na cabeça, mas os personagens viram bolinhas de massinha e voltam para os potinhos" (Diário de campo, Pré 1 $06 / 11 / 2018)$.

À medida que as crianças utilizam a massinha de modelar várias histórias ganham vida, se cruzam e viram uma só. Um cachorro com mochilinha não tem medo de ficar por perto de um dragão com fogo, espada e um escudo. O tempo permite que a interação ocorra e ela traz colaboração e criação entre as crianças. Não há um cronograma para o tempo de brincadeira com massinha, ela pode durar quinze minutos ou uma hora, a qualidade da experiência é que define o tempo, não o relógio. Nisto, faz-se necessária a postura do "saber ver”. Para Malaguzzi, é inútil afirmar que é muito difícil observar a prontidão das crianças. Na verdade, ela pode ser vista! Precisamos estar preparados para ver, já que tendemos a perceber apenas o que esperamos ver (MALAGUZZI, 2016, p. 90). No entanto, não há porquê ter pressa, pois segundo o autor, estamos propensos a nos tornarmos escravos do relógio "um instrumento que falsifica o tempo natural e subjetivo das crianças e adultos". Quanto ao tempo, Malaguzzi (2016, p. 84), ainda destaca que: 
Fernando Pessoa (1986) diz que a medição de tempo do relógio é falsa. Ela é certamente falsa no que se refere ao tempo das crianças - para situações nas quais o verdadeiro ensino e aprendizagem ocorrem, para a experiência subjetiva da infância. É necessário respeitar o tempo de maturação, de desenvolvimento das ferramentas do fazer e do entender, da emergência plena, lenta, extravagante, lúcida e em constante mudança das capacidades das crianças, essa é uma medição do bom senso cultural e biológico.

Para ele, há uma razão para a infância durar mais nos seres humanos: a natureza sabe quantos rios existem para serem cruzados e quantas trilhas precisamos repisar (MALAGUZZI, 2016, p. 85).

Ostetto e Silva (2018) destacam que precisamos de professores que ouçam mais do que falem, que experimentem mais do que sigam modelos, que reparem mais nos modos das crianças de serem e de expressarem o mundo. Para isso, consideram a necessidade de se garantir na formação, além de conhecimentos específicos sobre a área de atuação, saberes da ordem (do) sensível, que possibilitem a reflexão e a experiência nos âmbitos estético, artístico e cultural (OSTETTO; SILVA, 2018, p.185).

As autoras apontam que, no plano legal, percebem-se aspectos relacionados à dimensão estética e cultural na formação de professores, e há a explicitação clara da necessidade de se contemplar o desenvolvimento das crianças em diversas dimensões, no entanto,

[...] A tendência que transparece do conteúdo legal caminha na direção de fornecer instrumentais para a atuação docente, muito ligada a perspectivas que historicamente, vimos combatendo, haja vista que pouco olha para o sujeito-professor, privilegiando, ainda, o conteúdo de ensino, informações e habilidades (OSTETTO, SILVA; 2018, p.190).

Além do mais, não basta a inclusão da arte no currículo de formação de professores, embora nisso já tenhamos um avanço, é preciso também considerar a pessoa na pessoa do educador.

Lembrando o que Nóvoa (2009, p. 6) nos diz:

[...] que o professor é a pessoa, e que a pessoa é o professor. Que é impossível separar as dimensões pessoais e profissionais. Que ensinamos aquilo que somos e que, naquilo que somos, se encontra muito daquilo que ensinamos. Que importa, por isso, que os professores se preparem para um trabalho sobre si próprios, para um trabalho de auto-reflexão e auto-análise. 


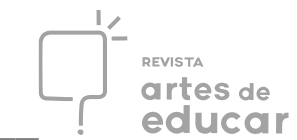

Na fala das professoras entrevistadas foi possível perceber que um movimento de reflexão das práticas está presente. Quanto a trabalhar numa instituição que privilegia uma educação voltada para a arte, a professora Rubi falou que "foi uma cobrança do meu eu”. Já a professora Esmeralda vê que o movimento de busca por cursos na área das artes lhe possibilitou uma aproximação maior com o universo artístico.

Sabe-se que as experiências vivenciadas ao longo da vida constituem um repertório cultural e estético, mas esse trabalho de autorreflexão e autoanálise, destacados por Nóvoa, são imprescindíveis quando se pretende trabalhar a dimensão estética, cultural e artística com as crianças. Que experiências tenho possibilitado? Que tempo disponibilizo para que possam olhar, ouvir e sentir as coisas ao seu redor? Que espaços apresento e crio para o estabelecimento de vínculos que priorizem o saber sensível? Estas perguntas são necessárias para que tenhamos clareza da dimensão sensível que propomos.

Por isso, destaco novamente a contribuição de Perissé (2014) quando diz que é preciso vontade de formar e vontade de formar-se.

Perissé (2014, p. 52) destaca que: Dominado por sua vez pela vontade de formar-se, o professor se deixa influenciar pela arte, administra conscientemente essa influência, pois a arte é formativa, por dar forma a sentimentos e ideias. Sentimentos se formam e se transformam em melodias, pinceladas enérgicas, desenhos, movimentos, ritmos, etc. Por essa razão:

Tenha ou não recebido formação estética na infância e na juventude, cabe ao professor procurá-la intencionalmente, uma formação para ouvir música e não apenas classificá-la em gêneros, para ver pintura e não apenas falar sobre a história da pintura, para ler um livro nas entrelinhas e não apenas encaixar autor e obra em movimentos literários. Refiro-me a autoeducação para ver e ouvir a arte (e para ver e ouvir tudo o mais), sem a preocupação de ver e ouvir unicamente aquilo que podemos enxergar e escutar todos os dias no plano das coisas úteis, manipuláveis e mensuráveis (PERISSÉ, 2014, p. $53)$.

$\mathrm{O}$ ato de formar-se esteticamente implica uma relação da pessoa consigo mesma atenta aos seus sentimentos, ideias e pensamentos e uma relação com o outro que o contempla como ser que também é sensível. No âmbito da formação docente precisamos considerar a importância de uma formação estética, que lance olhares e escutas sensíveis às crianças, assim poderão ser pensados tempos e espaços que favoreçam a ocorrência de experiências estéticas no cotidiano das crianças. 


\section{Considerações finais}

A realização das entrevistas foi uma das últimas etapas da pesquisa. Então foi possível ter claro que as professoras reconhecem que, para privilegiarem tempos e espaços aptos a promover experiências estéticas, necessitam de condições de trabalho e formação que lhes facilitem acesso ao estudo de suas práticas pedagógicas.

A vontade de conhecer e saber mais a respeito do tema foi muito evidente, tanto nas falas, quanto nas ações, mas segundo minhas observações e percepção das professoras, falta tempo para especialização, troca de conhecimentos entre os professores da escola, falta conhecimento específico durante a formação e conhecimento durante a prática da docência.

Por tudo isso, percebemos a necessidade de uma configuração política e educacional que olhe para a formação e vida dos professores, garantindo-lhes melhores salários, acesso a espetáculos, museus, cinemas, uma formação que privilegie tempos e espaços para que eles se expressem e ouçam os próprios sentimentos, anseios e aflições, para que exerçam a prática de um saber sensível com a própria vida e com a vida do outro, o colega, a criança.

Outra necessidade é a reflexão das práticas, uma ação que é estética, dotada de sensibilidade e que depende da pessoa do professor. Uma prática com olhares e escutas sensíveis às propostas lançadas, às singularidades das crianças do grupo, ao que elas gostam de fazer.

Favoreceremos tempos e espaços passíveis de experiências estéticas à medida que educarmos nosso olhar com a ampliação de nossos acervos culturais e artísticos, com a observação reflexiva sobre as crianças e nossas práticas. Não é uma tarefa que demanda esforço exclusivo das políticas educacionais, nem que demanda esforço isolado dos professores, mas uma combinação de esforços que vise a uma melhoria das experiências vividas na escola, que preze pela beleza das experiências.

Neves diz que refletir sobre a dimensão estética é apegar-se mais ao caminho do que à chegada (2017, p. 7): penso que esse é o objetivo, a atenção ao caminho, aos processos que se estabelecem no cotidiano das práticas educativas.

É o processo que nos permitirá enxergar que a arte é bem mais que um recurso interessante, que é imprescindível uma formação para lançar olhares e escutas sensíveis, um planejamento flexível que permita o encantamento com o que acontece no meio tempo, e o favorecimento de tempos e espaços para deslumbramentos. 


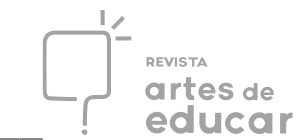

A qualidade dos tempos e dos espaços no cotidiano da Educação Infantil precisa ser estética, sensível. Isso implica disponibilizar tempo às experiências das crianças, espaços diversos focados numa multiplicidade de experiências, o respeito ao protagonismo infantil e a vivência conjunta dos professores com experiências que levam a descobertas das potencialidades corporais, imaginativas, poéticas.

Os professores, dotados do conhecimento de que um saber sensível é necessário ao nosso cotidiano e sociedade, precisam estar inscritos como parceiros de descobertas, de experiências estéticas.

Nas produções da infância a curiosidade aguça a imaginação, o tempo desacelerado permite a criação, o espaço a movimentação e tantas outras potencialidades. Por isso, é importante que os professores desenvolvam um saber estético, para que possam favorecer tempos e espaços que aflorem os sentidos das crianças e permitam a vivência da sensibilidade estética.

\section{REFERÊNCIAS}

BARBIERI, Stela. Interações: onde está a arte na infância? São Paulo: Blucher, 2012.

BRASIL. Diretrizes curriculares nacionais para a educação infantil. Secretaria de Educação Básica - Brasília: MEC, SEB, 2010.

GANDINI, Lella. Espaços educacionais e de envolvimento pessoal. In: EDWARDS, Carolyn. GANDINI, Lella. FORMAN, George. As cem linguagens da criança: a abordagem de ReggioEmilia na educação da primeira infância. Porto Alegre: Penso, 2016. p. 137-149.

HERMANN, Nadja. Razão e Sensibilidade: Notas sobre a contribuição do estético para a ética. Revista Educação e Realidade. N. 27(1): p. 11-26, jan./jun. 2002.

LARROSA, Jorge. Notas sobre a experiência e o saber da experiência. Revista Brasileira de Educação. N. 19, p. 20-28, jan./fev./mar./abr. 2002b.

MALAGUZZI, Loris. História, ideias e filosofia básica. In: EDWARDS, Carolyn. GANDINI, Lella. FORMAN, George. As cem linguagens da criança: a abordagem de ReggioEmilia na educação da primeira infância. Porto Alegre: Penso, 2016. p. 57-97.

MARTINS FILHO, Altino José. Minúcias da vida cotidiana no fazer-fazendo da docência na educação infantil.2013. 306 p. Tese (doutorado) - Universidade Federal do Rio Grande do Sul, Faculdade de Educação, Porto Alegre, RS. Disponível em:

<https://www.lume.ufrgs.br/handle/10183/72780>. Acesso em: 16 mar. 2019. 
MEIRA, Marly Ribeiro; PILLOTO, Silvia Sell Duarte. Arte, afeto e educação: a sensibilidade na ação pedagógica. Porto Alegre: Mediação, 2010, 139 p.

NEVES, Leonardo Longen. Lugares Educativos como Possibilidade para as Experiências Estéticas na Educação Infantil. 2017. 129 f. Dissertação (Mestrado em Educação Instituição de Ensino) - Universidade da Região de Joinville, Joinville/SC.

Disponível em:

<https://sucupira.capes.gov.br/sucupira/public/consultas/coleta/trabalhoConclusao/viewTrabal hoConclusao.jsf?popup=true\&id_trabalho=5011291> Acesso em 22 mar. 2018.

NOGUEIRA, Monique Andries. Música e educação infantil: possibilidades de trabalho na perspectiva de uma pedagogia da infância. Disponível em:

http://www.anped.org.br/biblioteca/item/musica-e-educacao-infantil-possibilidades-detrabalho-na-perspectiva-de-uma. Acesso em: 05 mar de 2019.

OSTETTO, Luciana Esmeralda. Sobre a organização curricular da Educação Infantil: conversas com professoras a partir das Diretrizes Curriculares Nacionais. Revista Zeroa-Seis, v. 19, n. 35, p. 46-68, jan-jun, 2017. Disponível em:

<https://periodicos.ufsc.br/index.php/zeroseis/article/view/1980-

4512.2017v19n35p46/34163>. Acesso em: 11 mai 2018.

OSTETTO, Luciana Esmeralda. SILVA, Greice Duarte de Brito. Formação docente, Educação Infantil e arte: entra faltas, necessidades e desejos. Revista Educação e Cultura Contemporânea, Tubarão, v. 15, n. 41, p. 260-287, Jan/Jun. 2018. Disponível em:

<file://C:/Users/User/Downloads/5902-16594-1-PB\%20(1).pdf >. Acesso em: 05 mar. 2019.

OSTETTO, Luciana Esmeralda. SILVA, Greice Duarte de Brito.Arte na formação docente para a educação infantil: Procura-se!.POIÉSIS - Revista do Programa de Pós Graduação em Educação - Mestrado - Universidade do Sul de Santa Catarina.v. 12, n. 21, p. 185-203, 2018. Disponível em:

<http://periodicos.estacio.br/index.php/reeduc/article/viewFile/4701/47965902>. Acesso em: 05 mar. 2019.

PERISSÉ, Gabriel. Estética e Educação. 2. Ed. Belo Horizonte: Autêntica Editora, 2014, 100 p.

ZAMPERETTI, Maristani Polidori. O Eu e o Outro na sala de aula - ocultando e revelando máscaras. 2007. 130 f. Dissertação (Mestrado em Educação) - Programa de PósGraduação em Educação, Universidade Federal de Pelotas, Pelotas.

\footnotetext{
${ }^{\mathrm{i}}$ Mestra em Educação pela Universidade Federal de Pelotas, Professora na rede do Estado do Rio Grande do Sul e na rede municipal de Pelotas. Especialista em Psicopedagogia Clínica e Institucional. Licenciada em Pedagogia. E-mail: hs.andreia@gmail.comORCID: https://orcid.org/0000-0002-5761-0024

ii Doutora e Mestra em Educação (PPGE/FaE/UFPel). Professora Adjunta no Centro de Artes da Universidade Federal de Pelotas, RS. Docente no Programa de Pós-Graduação em Educação (PPGE/FaE/UFPel), Mestrado e Doutorado, na Linha de Pesquisa "Formação de Professores: Ensino, Processos e Práticas Educativas". E-mail: maristaniz@ hotmail.com ORCID: https://orcid.org/0000-0001-9600-1988
}

Revista Interinstitucional Artes de Educar. Rio de Janeiro, V. 5, N.3-pág. 525-550 set-dez de 2019: "Educação: Corpo em movimento." - DOI: 10.12957/riae.2019.45781 